\title{
How can Open and Distance Learning effectively facilitate IT Education in Sri Lanka?
}

\author{
A. S. Karunananda* \\ Faculty of Information Technology, University of Moratuwa
}

The state university system has been frequently criticized for not producing adequate IT manpower for the development of the country. In responding to this issue, the Open University of Sri Lanka (OUSL) has been offering Computer Science, Computer Engineering and various basic IT courses through the distance mode for many years.

This study investigates whether a prior knowledge of IT contributes to improved performance in Computer Science education at the university level.

This research was carried out using two groups: students who concurrently follow Computer Science and a common IT course in the university and students who follow Computer Science but not a common IT course. Students performance records were used for the analysis.

In this research, it is empirically revealed that offering well-designed certificate or diploma programmes in IT at the pre-university level will be of immense benefit. This serves two purposes; firstly, such a programme could be used as a means for preparing students for the degree level Computer Science course. Secondly, it can strengthen IT manpower in the country, as IT knowledge of this level adequately serves the majority of IT needs in the country.

It is proposed that the OUSL should respond to this national need by offering more certificate or diploma courses in IT nationwide. Finally, it is also proposed that the OUSL should explore the possibility of private sector collaboration in offering certificate and diploma level programmes in IT nationwide.

\section{Introduction}

Information Technology (IT) is widely used in many day-to-day activities and has a tremendous impact on improving the quality of life. IT has also created new job opportunities and a knowledge of IT can also promote career development in almost all fields. Therefore, the learning of IT has been a theme of everybody comprising all age groups ranging from children to adults (Williams, Sawyer \& Hutchinson; 
1995). In Sri Lanka, it is a recognized fact that the IT knowledge of our children and general public is not adequate for national development. In fact, according to a survey conducted by the Department of Census and Statistics, only $10 \%$ of the population in the age group 15 to 59 shows adequate IT literacy (Satharasinghe, 2004). At present, the number of graduates in IT related fields, produced by the Sri Lankan university system is less than a thousand (Samaranayake, 2002). Although many institutions have come forward to promote IT education, they are unable to meet the national demand.

In this context, it is argued that the Open and Distance Learning (ODL) strategy adopted by the OUSL system can play a leading role in creating opportunities for a wider group of citizens to acquire IT knowledge. The ODL allows people to gain education regardless of either the geographical location or of the strict entry requirements to enter the conventional university system. For this purpose, the OUSL already has its own nation-wide network of regional and study centers through which all parts of the country could be reached.

This paper discusses the level at which the OUSL could promote IT education in the country through the ODL mode. Based on the research findings, it is revealed that the OUSL should facilitate Certificate level IT education as a means of preparing students for Degree Level IT, Computer Science and Computer Engineering courses. This will also generate a substantial amount of IT manpower for national development. It should be noted that a large part of the IT needs in the country could be met by Certificate and Diploma level IT education. Thus, Computer Science and Computer Engineering graduates can be used, where they are absolutely necessary for the development of the country. This paper also presents a new proposal for the OUSL to consider seeking private sector collaboration in offering IT programmes.

The paper is organized as follows. The first section briefly describes IT education in Sri Lanka, with an emphasis on secondary and tertiary level education. The next section discusses issues pertaining to IT, Computer Science and Computer Engineering education at the OUSL and defines the problem addressed in the paper. The final section is on the research into analysis and interpretation of students' performance in existing IT and Computer Science courses at the OUSL and concludes the paper with a note on further work. 


\section{IT education in Sri Lanka}

Information Technology (IT) emerged as a major application area of Computer Science in the late 1980s (Williams et al. 1995). However, IT has reached the general public faster than Computer Science or Computer Engineering. In reality, IT is more practical while Computer Science is more theoretical. Further, Computer Engineering is more hardware oriented. However, persons qualified in Computer Science and/or Computer Engineering are involved in the teaching of IT worldwide. In contrast to Computer Science and Computer Engineering, IT can be easily introduced at any level of education. For example, there can be IT programmes offered at the secondary education level, tertiary education level and the postgraduate level. In the present context, IT covers all computing related areas including Computer Science, Computer Engineering, Communication Technologies and Information Systems. As such developments in the related areas have naturally contributed to the rapid expansion of IT, and postulated the successor of IT as the popular field of Information and Communication Technologies (ICT).

Nowadays, IT knowledge is essential for every social group ranging from children to adults. As a result, there are various avenues for learning IT even through ODL methods. In this context, many distance education institutes have used various web-based materials to facilitate IT education. Some institutions offer online IT Certificate courses. In using IT, people have also moved beyond web-based technology to support distance education. For example, new software trends such as Agent technology have already been used in distance education for the preparation of distance learning materials (Karunananda, 2000a). Further, the OUSL have coined the concept of Virtual Day Schools for distance education (Perera, Karunananda, Ranasinghe \& Karunaratne, 2002). Learning Management Systems (LMS) and Virtual Classroom concepts are currently practiced by the OUSL.

Even though, IT education is an integral part of the need of the society, there is no national plan for IT education in Sri Lanka. In particular, secondary level education is yet to incorporate IT education into the school curriculum. Even at the university level, IT education must be revised in order to meet different levels of IT manpower needs in the country. In the current context, graduates not only IT, Computer Science and Computer Engineering, but also from other areas such as Physical Science and Engineering aim to enter the Software Industry. 
Over the last several years, only a very few Computer Science graduates joined the state university system as academics. Most graduates have chosen to join the software industry since this option is financially more attractive than being an academic (Karunananda, $2000 b)$. However, most of the job opportunities available in the software industry do not necessarily need a B.Sc. degree in Computer Science or Computer Engineering. Therefore, such needs can easily be fulfilled by using IT qualifications, which are below the degree level.

In order to discuss the real issues pertaining to IT education, the next section elaborates on the nature of IT education in Sri Lanka at various levels.

\section{IT at the Secondary education level}

At present, school children are attracted to IT education without proper guidance from the education system. Parents are also partly responsible for allowing their children to engage in IT education without a proper vision. This trend has lots of negative effects for education in general. Owing to the fascination of IT, many students are motivated to neglect other mainstream subject areas and follow a course in IT. Such students are more likely to think that, merely with a knowledge of IT, they could have better job opportunities. This is such a narrow and short term vision about a career path. It is a fact that unless IT persons continuously upgrade their knowledge, they cannot survive in their chosen careers in the field of IT.

It must be pointed out that students should learn IT, as a means of acquiring more and more knowledge in their respective subject areas. Otherwise, it is meaningless for everybody to be an IT person. In the very near future, a person with a first degree in IT, will not be able to survive without a postgraduate qualification or extensive industry qualification. In contrast, people in other areas will have a secure life if they have a substantial knowledge of IT.

At the time the original version of this paper was written, there was no properly designed curriculum or standard for IT education at the secondary education level. As a result, various institutions offered a large number of unstructured IT courses. This has only been treated as a business. This is why some IT training institutions tend to offer even incorrect material. IT education at the secondary education level should be promoted, however, there should be a proper vision on how IT education at this level should be promoted. Setting up a large number of IT training institutions at the national level will not solve 
this issue. In fact, it leads to an overflow of IT persons at lower levels, by neglecting the importance of other subjects such as Mathematics and Science. It will be yet another national disaster.

In this respect, it is pointed out that the ODL methodology would be the best mode to offer IT education for students at secondary education level. Even after IT has been introduced to the school curriculum, the OUSL can still provide training facilities for school children. This is because the school system requires a reasonable time period to acquire computer facilities and human resources to teach IT in schools. For example, the government's initiative to introduce a course on General Information Technology (GIT) at the school level suffers from various issues such as lack of qualified teachers, teaching materials and relevant infrastructure in IT.

\section{IT at the Tertiary education level}

IT education at tertiary level should go beyond teaching of user level IT, by incorporating other areas such as Computer Science and Engineering. All Sri Lankan universities now offer Computer Science/IT as a discipline for the bio science and physical science, 3year B.Sc. degree. In addition there are also 3 universities offering 4 year degrees in Computer Science, Computer Engineering or IT (University Statistics, 2004). However, most of the Computer Science courses offered for the 3-year degrees can easily fall under IT but do not provide a rigorous theoretical basis. There are also other IT courses at the university level, aiming at various programmes of education such as Engineering, Bioscience, Medicine, Arts, Commerce and Management. Undoubtedly, those should be promoted, yet there are many issues to be addressed in IT education at the university level.

Among other issues pertaining to IT education at the university level, the lack of qualified staff is a key issue. Ever since the introduction of Computer Science/Computer Engineering/IT into the university curricular, graduates of these courses preferred jobs in industry rather than in academia. Therefore, for many years, it has not been possible to strengthen the teaching and research capacity in IT and Computer Science at the university level. It is evident that the current salary structure of the university system can neither attract nor retain qualified personnel in IT related areas.

In view of this, IT education in the university system should be designed in such a way that the graduates will serve both academia 
and industry. The present day imbalance has caused serious issues in IT education that will affect the country in the long-term. In fact, the entire university system is already faced with this problem. Graduates with a strong component in Computer Science should be encouraged to proceed along the academic line. In contrast, graduates with more practical-based IT knowledge should be encouraged to work in industry. Further, students who could not obtain university education can also be trained at a technical level to work for the IT industry. It is a national waste if the country continues to use Computer Science and Computer Engineering graduates as software developers. Their services must be retained at the research and development level in the computer industry.

At the OUSL, every year more than 1000 students apply to follow Computer Science in the Department of Mathematics and Computer Science of the Faculty of Natural Sciences. However, due to infrastructure and human resource limitations, only $20 \%$ of the demand is met each year. The Faculty of Natural Sciences of the OUSL also offers a common course on IT to the students of the B.Sc. degree programme and the B.Sc Nursing degree programme. In addition, the Faculty of Engineering Technology of the OUSL also offers a diploma in computer technology, leading to a B.Tech. degree in Computer Engineering. This programme also caters to a very limited number.

\section{IT for Adult education}

It must be emphasized that IT education for adults is vital for the development of the country, due to at least two main reasons. Firstly, adults who are employed can proceed faster in their career path if they have IT knowledge. Secondly, unemployed adults could use IT knowledge as a means of exploring more job opportunities.

The OUSL has been established with the prime objective of encouraging adult education in Sri Lanka. Since the early 1980s, the OUSL has been offering various IT courses for adults. For example, the OUSL has been offering a set of very popular Computer Literacy courses for the last two decades (Rainford, Witharanage \& Vithanage, 1991). However, these courses do not meet the current IT needs of the country. In addition to the computer literacy course, the OUSL offers the above mentioned degree level computing courses for adults. The OUSL has already awarded some M.Phil degrees in Computer Science. In fact, the OUSL has been one of the leading universities offering M.Phil. degrees in Computer Science in Sri Lanka. The Master of Philosophy programmes at the OUSL have also been used as a 
mechanism to strengthen staff development locally at the postgraduate level. Nevertheless, the OUSL has not yet been successful in launching any MSc programmes in IT or Computer Science.

Several Sri Lankan Universities have now started offering MSc. Programmes in Computer Science and IT. At the time of writing this paper, five national universities and two private institutions have launched M.Sc. programmes in Computer Science aimed at people who have a first degree in any discipline. All these are offered to graduates who do not have a first degree in Computer Science. Therefore, such M.Sc. qualifications cannot be used for strengthening Computer Science education and research in the university system in general.

Having recognized the needs of the country, the Department of Mathematics and Computer Science of the Faculty of Natural Sciences of the OUSL has done some initial work towards offering Certificate Courses in Computer Applications (IT) and an M.Sc. in Computer Science. The next section will discuss the issues related to offering such programmes at the OUSL.

\section{IT education at the OUSL}

This section describes the challenges faced by the OUSL as an ODL institute in facilitating IT education in Sri Lanka. It is worth conducting research into this matter, since IT education through the distance mode has been very successful worldwide, but not in the OUSL. Therefore, it is argued that the OUSL should also be able to support nation-wide IT education more effectively. Here are some matters to be taken into consideration for the success of this exercise.

\section{IT for education}

Theoretically, using IT for education itself should be a strong research and development area in the OUSL. Nevertheless, this has not been done adequately. For example, the recent innovations such as the virtual classroom, which appears on the OUSL website, has been operating at an experimental level, and no formal research has been done to test the effectiveness of this approach. Although some work relating to IT for education at the OUSL has begun (Hoole, Rajendram $\&$ Gurusinghe, 2000), such work has never been used to address the issue of the effective use of IT for education at the OUSL. Research into the use of concepts of Virtual Day Schools (Perera et al., 2002) has also not been practically used as a means for exploiting IT for education at 
the OUSL. Due to infrastructural limitations, the Virtual Day School concept could not be tested at the OUSL. Some postgraduate level work, including Computer-Assisted Mathematics learning (Dissanayake \& Karunananda, 2000) and a Web-based student counseling and orientation system (Sivayogan, 2003) have also been developed but the results of the research have not been put into practice. The major reasons for not implementing those research outputs are infrastructure limitations in computer hardware, software and the networking environment.

In this sense, although the OUSL has done some research in IT, the current environment is not conducive to practically implementing the outcome of the research. It is argued that the OUSL should be more adaptive and dynamic and provide opportunities/facilities for experimenting with new trends. It should be noted that some of the conventional universities have already adapted the concept of distance learning for teaching IT. This is why research in IT education and finding new avenues is important. As it is explained later, this study has revealed a lot of findings, which can be used to explore new means of offering IT courses effectively through ODL.

\section{Delays in course approval}

When compared with other conventional universities, the OUSL requires a more lengthy process to be followed to obtain approval of a curriculum to offer a course. This process includes approval at the following levels: Departmental, Faculty, Curriculum and program development committee, By-laws committee, Senate and finally the Council of the university. Assuming that these meetings are summoned every month, the minimum time required for approval of a course turns out to be six months. However, this does not work so smoothly in reality due to two reasons. First, these meetings do not take place every month. Second, at some meetings, major changes are requested, in which case progress is delayed by another month at least. As far as a course in IT is concerned, six months is a substantially long time. As a result, at the time the approval is granted to offer a course, the course content would be outdated. Therefore, it would be advisable for the OUSL to be sensitive enough to speed up the process of course approval depending on the nature of the subject.

\section{Course development and Human resources}

When compared with other universities, it is much harder to prepare/design a course at the OUSL. This is because the teaching 
methodology adopted at the OUSL requires writing course materials/textbooks before offering a course. Preparation of good course material for the distance education mode is much more difficult than writing an ordinary textbook. It requires bringing in expertise in many areas including, subject matter, pedagogy and technology. These materials are designed to serve specific purposes; so, the presentation style is different from that of an ordinary textbook. Preparation of supplementary materials such as audio, video and practical guides, which are an integral part of the course materials, is also very time consuming.

Currently, some of the conventional universities (e.g. University of Moratuwa, University of Colombo) have planned to offer e-Learning courses are also facing problems pertaining to course development suitable for the ODL mode. In particular, finding subject matter experts with writing skills and identifying the appropriate pedagogy for developing e-Learning materials have been some major issues. Undoubtedly, lessons from the OUSL experience would be of great importance to the success of ODL exercises in conventional universities.

In addition the preparation of course materials for IT/Computer Science is difficult due to various reasons. First, the OUSL course approval procedure cannot comply with the speed of IT development. Second, it is extremely difficult to find course writers among qualified academics. Since IT personnel have enormous job opportunities offering very attractive emoluments, hardly any Computer Science academic outside the OUSL wishes to spend time writing courses for the OUSL.

During last ten years only two outsiders, offered to write courses in Computer Science (Dias, 1999; Ranasinghe \& Perera, 1999) for the Department of Mathematics and Computer Science at the OUSL. Most of the courses for Computer Science have been written by one author Karunananda, 1996a; Karunananda, 1996b; Karunananda 1997). Due to lack of human resources in IT at the OUSL, the same author has written many course material for the Computer Engineering courses offered by Faculties of Engineering Technology (Karunananda, 2000c) and Humanities and Social Sciences (Karunananda, 2000d; Karunananda, 2001b). Since the IT and Computer Science field evolves very rapidly, updating of these materials on a regular basis is imperative. This has also been practically very difficult due to the lack of human resources. It has also been noted that, the OUSL is not the 
first preference of the IT qualified persons who wish to become academics.

Over the last ten years the OUSL was hardly able to attract any postgraduate qualified IT or Computer Science persons to the Department of Mathematics and Computer Science, or the Department of Electrical and Computer Engineering. Instead, there were several instances, where qualified persons in Computer Science and Computer Engineering left the OUSL. This shows that not only attracting but also retaining qualified persons in IT related areas has been a big challenge for the OUSL. Although this issue applies to the other institutions, the situation is not as bad as in the OUSL. For example recently the Universities of Colombo, Moratuwa, Sri Jayawardenapura and Kelaniya have been successful in strengthening the academic staff capacity in IT and Computer Science. Most of these universities are offering separate degrees in Computer Science and IT.

\section{Problem definition}

The problem addressed in this paper can be defined as follows:

With regard to IT education, the OUSL has not identified the most appropriate level of IT education to cater to a wider group of citizens in the country.

\section{Research work}

Research has been carried out to analyze students' performance in the discipline of Computer Science over the last five years. Two experiments were carried out to see whether prior knowledge in IT contributes to improved performance in Computer Science in the university. These two experiments were aimed at testing the effect of pre-university and university first year IT knowledge on the study of Computer Science.

\section{Rationale for the research study}

The rationale behind this study is as follows. The study of the effect of knowledge of pre-university level IT is essential for the research, as the students intending to follow Computer Science are selected by conducting a selection test. The selection test has been a very effective means of identifying social impressions and expected standards about IT. The second study was done by using students' performance in a common IT course, in the first year of study, known as Computer 
Studies (Karunananda, 2001a) offered by the Faculty of Natural Sciences of the OUSL. This common IT course is offered to two categories of students, namely, students who have been selected to follow computer science as a discipline and to all other B.Sc. undergraduates. Therefore, analysis though this course is appropriate to measure the effect of a common IT course on the performance of Computer Science students. Both experiments were based on the data obtained from the IT division of the OUSL.

The overall experiment was conducted to investigate whether there is evidence of a need to promote IT education at a pre-university level.

\section{Analysis through Pre-University level IT Knowledge}

Computer Science has been the most popular subject with the highest demand in the Faculty of Natural Sciences of the OUSL. It was introduced in 1996. Every year more than a thousand students opt to register for Computer Science as a subject for the B.Sc. degree programme. However, due to limited infrastructure and human resources, the OUSL has to limit enrolment through a selection test. This test evaluates the pre-university level IT knowledge of the applicants.

The Computer Science Selection Test comprises two sections; namely, Computing IQ and General Knowledge in IT. Figure 1 shows the distribution of students' performance in the Selection Test. The research has shown that on the average, only $30 \%$ of the students were able to obtain more than 40 marks for the Selection Test. A majority of students who had passed the examination fall within the marks range of 40 to 50 . However, there are also a very few students who scored above 90 . 


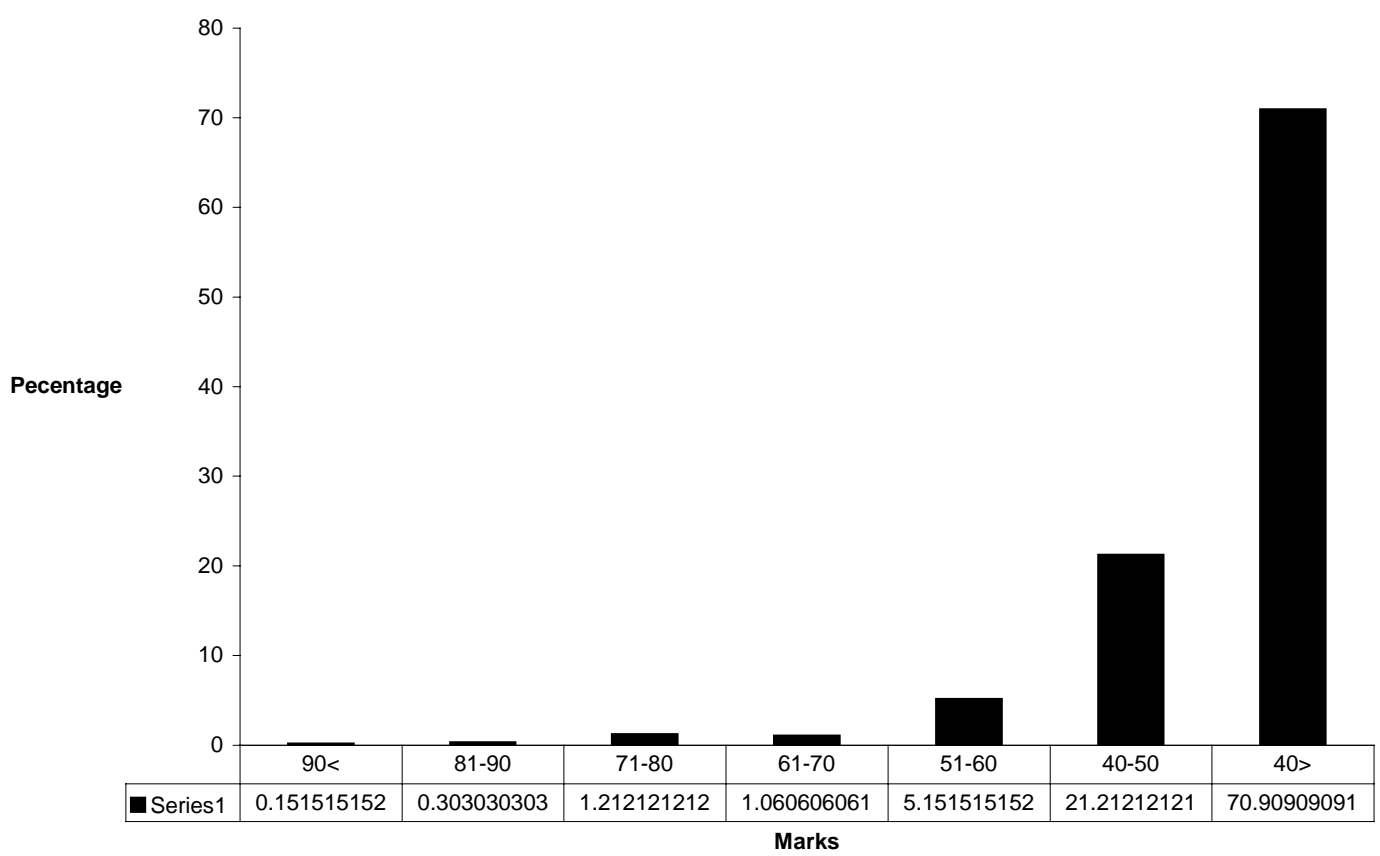

Figure 1 - Students performance in Selection Test

When analyzing the structure of the Selection Test, it was further noticed that $59 \%$ of the students had scored more than the pass mark (40), by answering the section on the General Knowledge in IT. Only $41 \%$ had scored by answering on Computing IQ. Figure 2 shows the pass-rate by answering the section on General Knowledge (59\%) and the section on Computing IQ (41\%).

High performance (59\%) in the section on IT General Knowledge shows that the general public is very much interested in IT education. This form of knowledge can be obtained by means of general reading, watching television, etc. Nevertheless, low performance $(41 \%)$ in the section on Computing IQ shows that the IT capability of the general public is not up to expectation. That means that although people are interested in IT, they do not have a proper aptitude for IT. One may argue that this can be concluded intuitively without conducting an experiment. However, such an argument cannot be generalized. For example, the results of the Law Entrance Selection Test conducted by the Department of Legal Studies of the OUSL shows that many students are weak in answering the section on General Knowledge. On the other hand, in the Computer Selection Test, there is also no significant evidence to show that students with (G.C.E) A/L 
Mathematics background have scored more in the IQ part. Of course, this may also be an intuitive expectation. This is why an analysis of results in the Computer Selection Test is important. However, since the gap between $41 \%$ and $59 \%$ is not too wide, IT aptitude in the society can be improved, if appropriate measures are taken. This is only a matter of ability and desire.



目 General Knowledge

$\square$ Computing IQ

Figure 2 - Performance in Computing IQ and General Knowledge

\section{Analysis through university first-year IT knowledge}

The course titled Computer Studies (Karunananda, 2001a) is the common course on IT for all students in the Faculty of Natural Sciences. Every year, on the average, more than six hundred students are registered for this course. It is the general impression that students who follow Computer Science, as a discipline, score better than the other students in Computer Studies. With this intuition, it was the aim to empirically show whether the course on Computer Studies improves the performance in courses on Computer Science. Therefore, performances of Computer Science students were considered for the research study. The pass-rate of Computer Science for those who have followed Computer Studies, is shown in Table 1. 
Table 1 - Pass rate in Computer Science of those who followed Computer Studies

\begin{tabular}{|l|l|}
\hline Academic Year & $\begin{array}{l}\text { Pass rate \% in } \\
\text { Computer Science }\end{array}$ \\
\hline $1996 / 1997$ & 76.47 \\
\hline $1997 / 1998$ & 100 \\
\hline $1998 / 1999$ & 95.45 \\
\hline $1999 / 2000$ & 89.29 \\
\hline $2000 / 2001$ & 93.33 \\
\hline Average & $91 \%$ \\
\hline
\end{tabular}

As shown in the Table 1, the average pass rate in Computer Science for those who offered Computer Studies in the same year is $91 \%$. It should be noted that the first batch has shown a pass-rate close to $76 \%$. This was quite natural, since the first batch faced difficulties such as not receiving course materials on time and cancellation of some day schools due to scarcity of lecturers. Even if the pass rate of $76.47 \%$ of the year 1996/1997 is removed, the average pass rate still remains at 95. This further supports the argument that Computer Studies has contributed to improve the performance in Computer Science. In any case, with or without the result of year 1996/97 with the passage of time, the effect of Computer Studies on the performance of Computer Science has become evident. On the other hand, there are some students who can perform very well without a prior knowledge in IT. Therefore, it is quite natural that about $9 \%$ of performance can be achieved regardless of previous knowledge in IT but this is an exception. However, our point is that prior IT knowledge can facilitate better performance in Computer Science to a great extent $(91 \%)$.

\section{Performance in Consecutive years}

Annual performance of students who have passed the Selection Test and offered Computer Science as a subject for their B.Sc. degree has also been analyzed. Figure 3 shows the performance of Computer Science students over the past three academic years. Note that, at the time of writing this paper, only three batches of Computer Science students have been produced by the OUSL. As shown by the performance in the first year, approximately $60 \%$ (on the average) passed the final examination at level 3 (L3). At higher levels (L4 and L5), the pass rate is higher than those at L3. This pattern has been repeated in all batches. As shown in Figure 3, on the average, students have performed better at the higher levels. This exhibits the 
fact that our curriculum has supported the development of students throughout our degree programme.



Figure 3 - Students' performance at consecutive levels

This shows that for each year, the previous year has provided the necessary foundation and the knowledge. However, although a particular year provides a basis for the education at the proceeding year, this does not imply that the pass rate should improve year by year. It is argued that this has happened since students still acquire fundamentals at each level. Stated in another way, if students start with a proper IT foundation, there should be a somewhat uniform pass rate at each level.

As shown by both analyses, the general public is very much interested in learning IT, computer science and computer engineering. However, a majority of people do not have the necessary capability in these subject areas. Otherwise, everybody should pass the Selection Test with very high marks for the Computing IQ part of the test. However, since there is a small percentage difference in performance between Computing IQ $(41 \%)$ and General Knowledge (59\%), it can be improved using a proper IT course at the pre-university level. It has also been very clear that most students learn IT for the first time in their life, after entering the university. Compared with other science subjects such as Biology, Mathematics or Chemistry, students do not have prior knowledge in IT before coming to the university. As a result, students take a 
substantial amount of time to acquire even the elementary jargon in IT related areas. The improvement of pass rates in Computer Science in consecutive years supports this point. One can argue that this is an expected feature of the OUSL system. However, it cannot be generalized since substantial numbers of Computer Science students at level 3 do not even become eligible to sit the final examination at level 3 . This is not the case in most other science subjects offered by the Faculty of Natural Sciences. This implies that our conclusions must be supported with empirical evidence. Therefore, although a lower pass rate can be intuitively expected at lower levels at the OUSL, for the discipline of Computer Science, this is very significant and also supported by empirical evidence.

At the OUSL, students following Computer Science perform better at higher levels, indicating that level 3 of the programme plays the role of giving the foundation for Computer Science. When considering the results in Table 1, the Computer Studies course (IT) has provided a good basis for Computer Science students.

The author's experience in teaching Computer Science at other universities has also convinced him that a majority of students attempt to acquire computer jargon in the first year of university education. For an example, a majority of Computer Science students at the University of Moratuwa are from the Colombo area, where students can get an exposure to computing before coming to the university. In this sense, there is a national need of improving students' IT knowledge before entering universities. This is crucial since secondary education in schools has not yet started to offer IT in schools in a proper manner. Even if IT education is started at schools, due to resource limitations, there will not be proper IT education at school level for some years. Therefore, it is argued that the OUSL could provide proper direction for IT education at the school level for many years in the future. Thus, the OUSL should explore the possibility of offering certificate level IT courses targeting more than five thousand students and adults per year.

\section{Conclusions and further work}

The research has empirically shown the need for facilitating IT education in the country, before the degree level. This can be achieved by introducing certificate or diploma level courses in IT island wide. The target audience can be considered as both school children and adults. As shown in the analysis, such a course can provide necessary exposure to IT, leading to degree level studies in IT and Computer 
Science. It should be noted that, although there are a large number of unstructured IT courses, they have not succeeded in this venture. If such courses have addressed the issue, at least by providing exposure in computing, there is no clear reason to say why first year undergraduates perform so poorly in Computer Science at the university level.

In view of the above, it is argued that the OUSL should take the initiative to offer certificate and diploma programmes in IT. Undoubtedly, in responding to the current IT needs in the country, the OUSL is the most appropriate institution to deliver IT knowledge nationwide in using ODL methodologies. Among other courses, IT courses can be easily offered in the distance mode. This is because, the modern ODL methodologies itself is IT. The existing infrastructure of regional and study centres of the OUSL can be effectively and readily used for this purpose. As compared with other institutions, this is a unique strength that the OUSL can use to disseminate IT knowledge nationwide. In case, infrastructure capacity is too limited to offer these certificate courses in some parts of the country, it is proposed to explore the possibility of obtaining support from private sector IT institutions. This is possible as some private sector IT institutions are also in the process of developing their nationwide networks. In view of the proposed huge expansion to the OUSL IT infrastructure through the assistance of the Asian Development Bank, the OUSL has become more eligible to be the leader of ODL in the country.

A realistic strategy for the OUSL could be to explore the possibility of obtaining private sector collaboration for certificate courses in IT. Many universities have already established private sector partnerships for degree programmes. For example, the Indira Gandhi National Open University (IGNOU) in India has already been successful in this exercise. The Bachelor of Information Technology (External) degree, University of Colombo, Sri Lanka is also offered with private sector collaboration. There are many other private sector institutions that collaborate with foreign institutions to offer foreign degrees. If private sector participation has worked for offering a degree programme, there is no reason why a certificate course in IT cannot be run in that mode. With this approach, the OUSL can limit its involvement in quality assurance and examinations of the certificate courses. Students can select any institution offering the OUSL courses, learn from them and sit for the examination conducted by the OUSL. 
Hence, it is concluded that in responding to the current IT needs of the country, the OUSL in collaboration with the private sector can be the leader of ODL infrastructure and IT education in the country.

\section{Acknowledgements}

I acknowledge the provision of data by the Information System Manager of the OUSL for this research. I am also grateful to Dr. Gamini Kulatunga and Dr. R.P.D. Silva, Department of Agricultural and Plantation Engineering of the OUSL for their comments on this paper.

\section{References}

Dias, G. K. A. (1999). Object-Oriented Programming. Colombo: Open University of Sri Lanka.

Dissanayake, S. N. \& Karunananda, A. S. (2000). PC-Based Mathematics Learning. In Proceedings of South East Asian Regional Computer Confederation (SEARCC2000) 26th - 29th November 2000. Manila, Philippines.

Hoole, D., Rajendram, M. \& Gurusinghe, D. (2000). Instituting Web-based chemistry teaching at the Open University of Sri Lanka. Chemistry in Sri Lanka, 17, 2, 33-34.

Karunananda, A. S. (2001a). Computer Studies (Revised edition). Colombo: Open University of Sri Lanka.

Karunananda, A. S. (2001b). Information Technology. Colombo: Open University of Sri Lanka.

Karunananda, A. S. (2000a). An Intelligent Agent for Distance Learning. In Proceedings of South East Asian Regional Computer Confederation (SEARCC2000) 26th - 29th November 2000. Manila, Philippines.

Karunananda, A. S. (2000b). Computer technology \& future of Sri Lankan society. In Proceedings of the 56th Annual session, Sri Lanka Association for the Advancement of Sciences (SLAAS) (pp. 289). November 2000, Colombo.

Karunananda, A. S. (2000c). Knowledge Engineering. Colombo: Open University of Sri Lanka.

Karunananda, A.S. (2000d). The Internet Technology. Colombo: Open University of Sri Lanka. 
Karunananda, A. S. (1997). Deductive Reasoning and Prolog for Artificial Intelligence. Colombo: Open University of Sri Lanka.

Karunananda, A. S. (1996a). Introduction to Information Systems. Colombo: Open University of Sri Lanka.

Karunananda, A. S. (1996b). Programming perspectives and Languages. Colombo: Open University of Sri Lanka.

Perera, B., Karunananda, A. S., Ranasinghe, D. D. M. \& Karunaratne, T. M. (2002). Virtual Day School for Distance Education - An Approach to ELearning, In Proceedings of the 21st National IT Conference, Computer Society of Sri Lanka. (pp156-160). 10-11 July 2002. Colombo.

Ranasinghe, N. \& Perera, B. (1999). Digital Electronics Fundamentals. Colombo: Open University of Sri Lanka.

Rainford, M. S., Witharanage, A. \& Vithanage, H. G. V. T. (1991). Pascal Programming. Colombo: Open University of Sri Lanka.

Sivayogan, S. (2003). On-line orientation and counseling for distance learning. MSc thesis, Informatics Institute of Technology.

Samaranayake, V. K. (2002). An Overview of Human Resources - Needs, Availability and Plans for the Future. In Proceedings of the 21st National IT Conference. Computer Society of Sri Lanka. (pp 4-11), 10-11 July, 2002. Colombo.

Satharasinghe, A. (2004) Computer literacy of Sri Lanka. Department of Census and Statistics, Sri Lanka. Available online at: www.statistics.gov.lk/cls2004/index.htm.

Williams, B. K., Sawyer, S. C. \& Hutchinson, S. E. (1995). Using Information Technology. Richard D. Irwin, INC.

University Statistics (2004). Sri Lanka University Statistics, Sri Lanka: UGC. 